\title{
MGA APPROACH FOR OPTIMIZATION OF DISTRIBUTED GENERATION PARAMETERS IN A POWER SYSTEM NETWORK
}

\author{
J.Baskaran ${ }^{1}$, D.SivaKumar ${ }^{2}$,C.Nayanatara ${ }^{3}$
}

\begin{abstract}
The introduction of Distributed Generation (DG) devices for power system improves the stability, reduction in losses and increase in the cost of generation. In this paper Micro Genetic Algorithm (MGA) is used to optimize the various parameters. The various parameters taken into consideration are their type, location and size of the DG devices. The simulation was performed on a distribution system with various types of DG's and modeled for steady state studies.) The results reveal the benefits of the proposed method, for solving simultaneous optimization problems of DG devices in a power system network.
\end{abstract}

Index Terms - Customer Benefit, Distributed Generation, Micro Genetic Algorithm, Location, Size

\section{INTRODUCTION}

DG means a small-scale power station for the need for satisfying local load different from a traditional or large Central power plant [1]. Right from traditional to nontraditional there are various methodologies used in the application of DG. The DG introductions have technical merits in fuel cells, photovoltaic, biomass, wind, geothermal and gas turbine. It includes voltage profile improvement, loss reduction and improves system reliability.

In a highly congested area the benefit of DG is more predominant [17]. The location of DG should be carried out considering its size and location. The placement should be optimal in order for maximum customer benefit and minimum congestion of DG implemented in the network. The improper placement will lead to reduction in system losses and sometimes it may even collapse the entire system.

The two broad paradigms for maximizing welfare is cost free and non cost free methods. The marginal cost involved is nominal (not capital cost) in the former method. The later method includes generation rescheduling and prioritization and curtailment of loads/Transactions.

The benefits of DGs in power system are justified by numerous techniques. The location of DG placement on the basis of Location Marginal Pricing (LMP) is proposed in Ref. [4]. The investment planning strategy was given by Khattam. [18]. Mithulananthan has used GA for placement of DG to reduce the losses [14]. Celli have used a penetration level assessment for the placement of DG [6]. Moghadass has modeled different DG units based on power flow studies by using backward/forward algorithm [16].Zareipour has given current status and challenges in

\footnotetext{
J.Baskaran ${ }^{1}$, D.SivaKumar ${ }^{2}$,C.Nayanatara

${ }^{1}$ Department of Electrical and Electronics Engineering, AdhiParasakthi Engineering College, Professsor/Head, Melmaruvathur. 2Department of Information Technology, Eswari Engineering College, Chennai
Professsor.

3 Department of Electrical and Electronics Engineering, Sri SaiRam Engineering College, Research Scholar, Chennai.
}

Distributed generation [8]. Modeling of distributed generations in a three phase distributed load flow and modeling of wind farms is derived in [5] and [10].

The objective of this paper is to develop an algorithm for finding and choosing the optimal location of DG devices, for power loss reduction, which relieves congestion and reduces the losses, based on Generation rescheduling, load curtailment and with generation rescheduling with load curtailment with DG devices. Placing the DG devices of various types in various locations has multiple advantages. For the proposed objective function simultaneous optimization of location and size is determined. The problem is analyzed by Micro Genetic Algorithm.

Rest of the paper is organized as follows: mathematical expressions for finding optimal sizes and location are discussed in Section II. Section III represents the objectives of distributed generation planning with problem formulation. Section IV presents MGA implementation for optimal sizing of DG and Section $\mathrm{V}$ gives simulation studies and numerical results obtained. The contributions and conclusions are summarized in Section6.

\section{MATHEMATICAL MODELING OF DG DEVICES}

\section{A. DG Devices}

The DG size is very important for placing in a particular bus as the losses are decreased to a minimum value and starts increasing above the size of DG (i.e. the optimal DG size) at that location [2]. The increase in size leads to maximize the losses value and it may overshoot the losses of the base case. The proper location of DG plays an important role in minimizing the losses, maximizing the customer benefit and minimizing the voltage deviation index. The modeling of DG is very important to achieve the objective

The Unity power factor modeling is done in PV cell is model, wind as a variable reactive model and gas turbine is modeled as a constant voltage model. A DG source has a constraint and it can be formulated as

$$
P_{G}^{\min } \leq P_{G} \leq P_{G}^{\max }
$$

Considering the output with reactive power of the DG, as it plays a major role, the bus connected to the DG can be modeled in three major cases [3] based on their characteristics in terms of real and reactive power delivering capability as follows:

1) Case 1: Real Power injection by DG

2) Case 2: Reactive Power injection by DG

3) Case 3: Real Power injection but Reactive Power consumption by DG.

The primary energy of DG may be injected to grid by a synchronous or asynchronous electric machine which is directly connected to the grid or by means of power 
electronic interface or a combination of electric machine and power electronic interface. The modeling of different DGs is done as follows:

\section{Modelling of PV cell}

The conversion of solar Energy into Electrical energy is done by PV system. Their DC power output is converted via an inverter into $\mathrm{AC}$ power so that it is compatible with grid. The DG model depends on control circuit and in general it is designed to control $\mathrm{P}$ and $\mathrm{V}$ independently it is modelled as a PV node. When P and Q are controlled independently it is modelled as a PQ node.

The power factor is unity and the necessary condition for minimum loss is given by equation 2 .

$$
P_{i}=P_{D G i}-P_{D i}=\frac{1}{A_{i j}} \sum_{\substack{j \neq 1 \\ j \neq i}}^{n}\left[\left(A_{i j}\right) P_{j}-B_{i j} Q_{j}\right)
$$

From the above equation we obtain the following relationship

$$
\mathrm{P}_{\mathrm{DGi}}=\mathrm{P}_{\mathrm{Di}}-\frac{1}{A_{\mathrm{ij}}} \sum_{\substack{\mathrm{j} \neq 1 \\ \mathrm{j} \neq \mathrm{i}}}^{\mathrm{n}}\left[\left(\mathrm{A}_{\mathrm{ij}}\right) \mathrm{P}_{\mathrm{j}}-\mathrm{B}_{\mathrm{ij}} \mathrm{Q}_{\mathrm{j}}\right)
$$

$\mathrm{A}_{\mathrm{ij}}$ and $\mathrm{B}_{\mathrm{ij}}=$ loss coefficients.

$\mathrm{P}_{\mathrm{j}}=$ real power injected to bus $\mathrm{j}$

$\mathrm{Q}_{\mathrm{j}}=$ reactive power injected to bus $\mathrm{j}$

$\mathrm{N}=$ number of buses

2. Synchronous compensators such as gas turbines

The type 2 DG has synchronous condenser and it supply only reactive power to improve voltage profile. The optimal DG placement is determined by differentiating the loss equation on either side with respect to $Q_{i}$. The power factor for type 2 will be zero and the optimal DG size for every bus in the system is given by equation 3 .

$$
\mathrm{Q}_{\mathrm{DGi}}=\mathrm{Q}_{\mathrm{Di}}-\frac{1}{\mathrm{~A}_{\mathrm{ij}}} \sum_{\substack{\mathrm{j} \neq 1 \\ \mathrm{j} \neq \mathrm{i}}}^{\mathrm{n}}\left[\left(\mathrm{A}_{\mathrm{ij}}\right) \mathrm{Q}_{\mathrm{j}}-\mathrm{B}_{\mathrm{ij}} \mathrm{P}_{\mathrm{j}}\right)
$$

\section{Modelling of wind turbine}

In an induction generator both active and reactive powers are functions of slip.

$$
\begin{aligned}
& \mathrm{P}=\mathrm{P}(\mathrm{V}, \mathrm{s}) \\
& \mathrm{Q}=\mathrm{Q}(\mathrm{V}, \mathrm{s})
\end{aligned}
$$

Where $\mathrm{P}$ and $\mathrm{Q}$ are the active and reactive produced, the induction generator slip is denoted by's' and the bus voltage is ' $\mathrm{V}$ '. Assuming the dependency of $\mathrm{Q}$ is very low and $\mathrm{P}$ is constant the expression (5) can be reduced as follows:

$$
\mathrm{P}=\mathrm{P}_{\mathrm{s}}=\text { constant }
$$$$
\mathrm{Q}=\mathrm{f}(\mathrm{V})
$$

$$
Q=\sqrt{\left(E_{q} \mid X_{d}\right)}-P^{2}-\frac{V^{2}}{X_{d}}
$$

No load voltage Eq is maintained constant and $\mathrm{X}_{\mathrm{d}}$ is the synchronous reactance and $\mathrm{V}$ is the generator terminal voltage. The parameters of wind turbine include cut-in wind speed and rated wind speed and typical values of them are $3.5 \mathrm{~m} / \mathrm{s}, 25 \mathrm{~m} / \mathrm{s}$ and $14 \mathrm{~m} / \mathrm{s}$.

$$
P_{\text {wind }}(t)=0.5 \alpha \rho(t) A v(t)^{2}
$$

Where $\alpha$ is the Albert Betz constant, $\rho(t)$ is air density, A is area swept by turbine rotor, and $\mathrm{v}(\mathrm{t})$ is the wind speed. Maximum power rating of wind station is fixed by taking averages of all day powers calculated by using the equation. For this type of DG the power factor varies between 0 to 1.The maximum DG capacity for renewable DGs like Solar and Wind is calculated from the average power estimated by irradiance and wind speed. The average power generated by the wind turbine is $0.471 \mathrm{p} . \mathrm{u}$.

\section{OBJECTIVES OF DISTRIBUTED GENERATION PLANNING}

\section{A. Congestion Minimization}

One important factor that can hinder a desired trade of power is congestion of the transmission network. If a large enough capacity is available on the transmission system, we can allocate the power supply and demand so as to maximize social welfare [9]. However, as the margins of transmission capacity become scarce, there is a greater chance that the desired trade will have to be altered because of congestion. From a customer's viewpoint, congestion can also change the cost of electricity drastically from what is expected therefore, aggregate loading rate of transmission paths as an index of network congestion is introduced.

The CONgestion INDex(CONIND) is given by

$$
\text { CONIND }=\sum_{k \in B} \beta_{k}\left(P_{k} \div P_{k}^{\max }\right)^{2}
$$

Where $\mathrm{P}_{\mathrm{k}}$ is the active power flow on branch $\mathrm{k}$, and $\mathrm{P}_{\mathrm{k}}{ }^{\max }$ is the capacity; $\mathrm{B}$ is the set of all branches. By minimizing the above equation, power flows can be kept away from congestion as much as possible. $\beta_{\mathrm{k}}\left(0 \leq \beta_{\mathrm{k}} \leq 1\right)$ represents the weighting factor which varies between 0 to 1 that reflects the relative importance of the congestion in the network. At any instant transmission systems can fall into emergency operating conditions if a major fault occurs. The objective of congestion Index is to take action or control measures to relieve congestion of transmission networks. The bus having the minimum congestion percentage will be the optimum location of DG.

\section{Equality constraints:}

The modelling of transmission network is done by balancing the power equation at each node in the network.

$$
\begin{aligned}
& \mathrm{P}_{\mathrm{i}}=\mathrm{P}_{\mathrm{Gi}}+\mathrm{P}_{\mathrm{DGi}}-\mathrm{P}_{\mathrm{Di}} \\
& Q_{\mathrm{i}}=Q_{G \mathrm{i}}-Q_{D \mathrm{i}}
\end{aligned}
$$

\section{Inequality constraints:}

Generation limits. Generating limits are specified as upper and lower limits for the real and reactive power outputs.

Real power generation limits:

$$
P_{G i}^{\min } \leq P_{G i} \leq P_{G i}^{\max }
$$

Reactive power generation limits:

$$
Q_{G i}^{\min } \leq Q_{G i} \leq Q_{G i}^{\max }
$$

Line flow limit: The constraint validates for the absolute power flow both at sending and receiving ends of particular line to be within the upper limit of the line.

$$
\begin{aligned}
& S_{i j} \leq S_{i j}^{\max } \\
& S_{j i} \leq S_{j i}^{\max }
\end{aligned}
$$

Bus voltage limit: Voltage limits refer to bus voltage to remain within an allowable narrow range of levels.

$$
V_{i}^{\min } \leq V_{i} \leq V_{i}^{\max }
$$

For base case OPF,

$$
P_{D G \mathrm{i}}=0
$$

For load bus,

$$
P_{\text {Gi }}=0
$$

Where

$$
\begin{array}{ll}
\mathrm{N} & =\text { total number of buses in the system; } \\
\mathrm{P}_{\mathrm{Gi}} & =\text { total real power generated at bus } \mathrm{i} ; \\
\mathrm{P}_{\mathrm{Di}} & =\text { total real power demand at bus } \mathrm{i} ;
\end{array}
$$




$$
\begin{array}{ll}
\mathrm{P}_{\mathrm{DGi}} & =\text { the power supplied by the DG at bus } \mathrm{i} . \\
\mathrm{V}_{\mathrm{i}} & =\text { the voltage at bus } \mathrm{i} ; \\
\delta \mathrm{i} & =\text { the power angle at bus } \mathrm{i} ;
\end{array}
$$

Bij \& Gij = the susceptance and the conductance of the line $\mathrm{ij}$;

$\mathrm{Q}_{\mathrm{Gi}} \quad=$ reactive power generated at bus $\mathrm{i}$;

$\mathrm{P}_{\mathrm{Gi}}{ }^{\text {max }}$ and $\mathrm{P}_{\mathrm{Gi}}{ }^{\text {min }}=$ upper and lower real power generation limits of generator at bus $\mathrm{i}$;

$\mathrm{Q}_{\mathrm{Gi}}{ }^{\max }{ }^{2} \mathrm{AQ}_{\mathrm{Gi}}{ }^{\min }=$ upper and lower reactive power generation limits of generator at bus $\mathrm{i}$;

$\mathrm{V}_{\mathrm{i}}^{\max }$ and $\mathrm{V}_{\mathrm{i}}^{\min }=$ upper and lower limits of voltage at busi;

$\mathrm{S}_{\mathrm{ij}} \& \mathrm{~S}_{\mathrm{ji}} \quad=$ the complex power transfer from bus $\mathrm{i}$ to bus $\mathrm{j}$ and from bus $\mathrm{j}$ to bus $\mathrm{i}$;

The bus having the maximum customer benefit and minimum cost will be the optimum location of DG.

\section{B. Loss Minimization}

The Optimal allocation of distributed Generation includes planning to obtain maximum benefit by minimizing total real power loss in the system [20]. The loss in the system is the total energy management which can be calculated using the below equation

$$
\begin{aligned}
& P_{L}=\sum_{i=1}^{N} \Sigma_{j=1}^{N}\left[\propto_{i j}\left(P_{i} P_{j}+Q_{i} Q_{j}\right)+\beta_{i j}\left(Q_{i} P_{j}+P_{i} Q_{j}\right)\right] \\
& \text { where } \propto_{i j}=\frac{\tilde{r}_{i j}}{V_{i} V_{j}} \cos \left(\delta_{i}-\delta_{j j}\right) \\
& \beta_{i j}=\frac{r_{i j}^{2}}{V_{i} V_{j}} \sin \left(\delta_{i}-\delta_{j}\right) \\
& Z_{i j}=x_{i j}+j x_{i j} \\
& \text { are the } \mathrm{ij}^{\text {th }} \text { element of }\left[\mathrm{Z}_{\text {bus }}\right] \text { matrix } \\
& \alpha_{\mathrm{i}}=\frac{\partial \mathrm{P}_{\mathrm{L}}}{\partial \mathrm{P}_{\mathrm{i}}}=2 \alpha_{\mathrm{ii}} \mathrm{P}_{\mathrm{i}}+2 \sum_{\substack{\mathrm{j} \neq 1 \\
\tilde{j} \neq \mathrm{i}}}^{\mathrm{n}}\left[\left(\alpha_{\mathrm{ij}}\right) \mathrm{P}_{\mathrm{j}}-\beta_{\mathrm{ij}} \mathrm{Q}_{\mathrm{j}}\right)
\end{aligned}
$$

Sensitivity Index is evaluated at each bus by using the values obtained from the base case load flow. The bus having lowest loss sensitivity factor will be best location for the placement of DG.

\section{HYBRID APPROACH FOR PLACEMENT AND SIZING OF DG}

Heuristic methods may be used to solve complex optimization problems. Thus they are able to give a good solution of a certain problem in a reasonable computation time, but they do not assure to reach the global optimum. The GA's (Genetic Algorithm) start with random generation of initial population and then the selection, crossover and mutation are produced until the best population is found.

A Genetic Algorithm is based on global searches technique and the mechanisms of natural selection and techniques. Accordingly, some numbers of individuals are selected for such a group. Then the grouping is repeated and individuals are selected to form couples to begin the crossover.

\section{Objective function}

The main objective of this paper is to study the effect of placing and sizing the DG in all system indices. Multi objective optimization is performed by combining the all indices with appropriate weights. The Objective Function is given as

$\mathrm{F}(\mathrm{Min})=\left(\mathrm{W}_{1 * \mathrm{PL}}+\mathrm{W}_{2} * \mathrm{TSW}\right)$

Subjected to the constraint

$$
\sum_{k=1}^{2} W_{K}=1
$$

Where $\mathrm{W}_{\mathrm{k}} €[0,1]$

The weights are indicated to give the corresponding importance to each impact indices for the penetration of DGs. In this analysis Total Social Welfare (TSW) and Power Loss (PL) is given equal weight of 0.5 .

\section{Encoding}

The main objective of the optimization is to find the best locations for the given number of DG devices within the defined constraints. The configuration of DG device is obtained by three parameters: the location of the devices, their types and their rated values. Each individual is represented by $\mathrm{N}_{\mathrm{DG}}$ number of strings, i.e., and number of DG devices to be used for this optimization problem.

The last value represents the DG size and can take values from 0 to $10 \mathrm{MW}$

\section{Initial Population}

The initial population is generated from the following parameters. $\left[\mathrm{N}_{\mathrm{DG}}\right.$ is the number of $\mathrm{DG}$ devices to be located, the possible location of the devices i.e., $\mathrm{N}_{\text {location, }}$ types of the devices i.e., $\mathrm{N}_{\text {types. }}$

The first, a set of $\mathrm{N}_{\mathrm{DG}}$ number of strings are produced. For each string the first value is randomly chosen from the possible locations $\mathrm{N}_{\text {location }}$.

The second value, which represents the types of DG devices, is obtained by randomly drawing numbers among the selected devices.

The third value of each string, which contains the rated values of the DG devices, is randomly selected between +1 and -1.To obtain the entire initial population, the above operations are repeated $\mathrm{N}_{\text {ind }}$ times. The objective function is computed for every individuals of the population.

The objective function is defined in order to quantify the impact of DG devices on the state of power system network. The inverse of the objective function is used to compute the fitness value of each individual in the population.

Fitness=1/Objective function +1

\section{Reproduction}

The biased Roulette wheel selection is used in this paper for reproduction, according to their fitness values; the individual is selected to move to a new generation.

\section{Crossover}

Crossover is a technique which is used to rearrange the information between the two different individuals and produce new one. The crossover is applied in each successive generation with a certain probability, known as the crossover fraction or rate. In this paper two point crossovers is employed and the probability $\left(\mathrm{P}_{\mathrm{C}}\right)$ of the crossover is 0.75 .

\section{SIMULATION RESULTS}

The power flow studies are carried out with the help of $\mathrm{VC}++$ software package. The modified distribution system which has 30 nodes and 32 segments is used to verify the effectiveness of the proposed algorithm.

The location of DG device in various lines is simulated using MGA and the rated value for PV cell/wind turbine/gas turbine is automatically chosen and the corresponding decrease in Congestion and the reduction in loss are also tabulated in Table3. The solutions found by MGA indicate more locations; also the power loss reduction and minimization in congestion is efficient. 
Proc. of The Second Intl. Conf. On Advances In Computing, Control And Networking - ACCN 2015

Copyright (C) Institute of Research Engineers and Doctors, USA .All rights reserved.

ISBN: 978-1-63248-073-6 doi: 10.15224/ 978-1-63248-073-6-79

TABLE II.VOLTAGE DEVIATION TABLE WITH AND WITHOUT DG

\begin{tabular}{|l|l|l|l|}
\hline S.NO & \multirow{2}{*}{$\begin{array}{l}\text { VOLTAGE } \\
\text { RANGE }\end{array}$} & $\begin{array}{l}\text { TOTAL NUMBER OF } \\
\text { BUSES(BUS NUMBER) }\end{array}$ \\
\cline { 3 - 4 } & & $\begin{array}{l}\text { WITHOUT } \\
\text { DG }\end{array}$ & WITH DG \\
\hline 1. & $0.51-0.64$ & $4(3,6,15,29)$ & NIL \\
\hline 2. & $0.65-0.74$ & $6(2,13,17,21$, & NIL \\
& & $22,28)$ & \\
\hline 3. & $0.75-0.84$ & $7(1,5,8,9,11,2$ & NIL \\
& & $325)$ & \\
\hline 4. & $0.85-0.95$ & $9(7,12,16,18$, & $02(4,13)$ \\
& & $19,24,26,27,3$ & \\
& & $0)$ & $25(1,2,3,5,6,7,8,9,10$ \\
& & $4(4,10,14,20)$ & $, 12,14,15,16,17,19,2$ \\
& $0.95-1.05$ & & $0,21,22,23,24,25,26$, \\
& & & $28,29,30)$ \\
\hline 6. & $1.05-1.1$ & NIL & $3(11,18,27)$ \\
\hline
\end{tabular}

\begin{tabular}{|c|c|c|c|c|}
\hline Line & Device & $\begin{array}{c}\text { Rated } \\
\text { value in } \\
\text { MW }\end{array}$ & $\begin{array}{c}\text { \% Decrease } \\
\text { in } \\
\text { Congestion }\end{array}$ & $\begin{array}{c}\text { \%Power Loss } \\
\text { reduction }\end{array}$ \\
\hline 1 & 1 & 3.8 & 0.67 & 3.98 \\
\hline 2 & 3 & 0.35 & 2.86 & 8.56 \\
\hline 4 & 1 & 3.6 & 8.67 & 5.76 \\
\hline 6 & 2 & 2.8 & 12.78 & 0.53 \\
\hline 8 & 2 & 3.7 & 12.42 & 2.06 \\
\hline 12 & 1 & 1.8 & 11.86 & 19.00 \\
\hline 17 & 2 & 1.9 & 18.97 & 36.78 \\
\hline 22 & 3 & 2.2 & 12.76 & 32.78 \\
\hline 23 & 1 & 3.12 & 7.43 & 32.78 \\
\hline
\end{tabular}

The loading capability is increased to twice the normal loading condition and the real power flows in various lines is given in Fig.5.

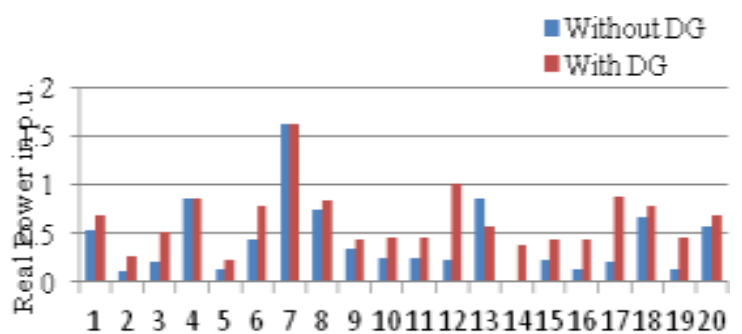

NodeNo

Fig5: Twice the loading condition with and without DG

The Power loss with and without DG for different loading conditions is tabulated in Table III and the optimal corresponding size of the DG is also indicated. The bus number and the corresponding DG size and real power loss are given in Fig.6.

TABLE III.LOSS WITH LOADING CONDITIONS

\begin{tabular}{|l|l|c|c|c|}
\hline $\begin{array}{l}\text { Types of } \\
\text { load }\end{array}$ & $\begin{array}{l}\text { Bus } \\
\text { location }\end{array}$ & $\begin{array}{l}\text { Optimal DG } \\
\text { Size(p.u) }\end{array}$ & $\begin{array}{l}\text { Power loss } \\
\text { with DG }\end{array}$ & $\begin{array}{l}\text { Power loss } \\
\text { without DG }\end{array}$ \\
\hline $\begin{array}{l}\text { Peak } \\
\text { Load }\end{array}$ & 12 & 0.68 & 7.32 & 11.43 \\
\hline
\end{tabular}

\begin{tabular}{|l|c|c|c|c|}
\hline $\begin{array}{l}\text { Medium } \\
\text { Load }\end{array}$ & 7 & 0.47 & 5.21 & 8.56 \\
\hline $\begin{array}{l}\text { Low } \\
\text { Load }\end{array}$ & 21 & 0.13 & 2.56 & 4.89 \\
\hline
\end{tabular}

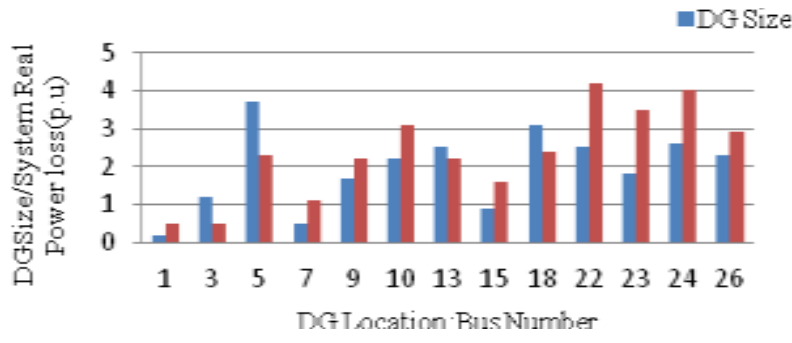

Fig6: Optimal DG location

The location of DG device in various lines is simulated using MGA method and the rated value for PV cell/wind turbine/gas turbine is automatically chosen and the corresponding decrease in congestion and the reduction in loss are also tabulated in Table IV.

The results reveal the close probity of the results obtained. Also the MGA method gives more number of lines and better result than conventional optimization techniquees.

\section{TABLE IV OPTIMIZATION OF DG PARAMETERS} A) MICRO GENETIC ALGORITHM

Indian NTPS system are considered as a test system in this work and on comparing both there is not much difference in the accuracy of the result and on a closer look into them Simulated annealing outperforms the GA. The following case studies are addressed for both the test cases.

Case (i) Generation Rescheduling (140 $\uparrow$ )

Case (ii) Generation Rescheduling with DG Devices (150个) Case (iii) Generation Rescheduling with load shedding (155个)

Case (IV) Generation Rescheduling with load shedding and DG Devices (155个)

\section{Indian utility-NTPS23 bus system}

The Indian utility Neyveli Thermal Power Station (NTPS)-23 bus test system is shown in Fig.7. A 100 MVA. $400 \mathrm{KV}$ base is chosen. All the case studies are analyzed.

The result below gives the total generation, total load, loss, objective function and the corresponding time taken for the simulation in Indian utility system is indicated. It is observed that MGA takes lesser converging time. The results indicate that MGA is superior to all optimization techniques.

TABLE V OPTIMIZATION OF OBJECTIVE FUNCTION FOR 4 CASES 


\begin{tabular}{|c|c|c|c|}
\hline $\begin{array}{l}\text { Case } \\
\text { studies }\end{array}$ & $\begin{array}{l}\text { Load } \\
\text { Increased }\end{array}$ & $\begin{array}{l}\text { Generati } \\
\text { on Cost } \\
\text { in }(\$ / h r)\end{array}$ & $\begin{array}{l}\text { Real } \\
\text { Power loss } \\
\text { in MVA }\end{array}$ \\
\hline Case (i) & $130 \%$ & 643.56 & 16.78 \\
\hline Case (ii) & $150 \%$ & 665.78 & 23.89 \\
\hline Case (iii) & $150 \%$ & 672.41 & 19.27 \\
\hline Case (iv) & $155 \%$ & 643.34 & 28.11 \\
\hline
\end{tabular}

\begin{tabular}{|l|l|}
\hline \multicolumn{1}{|c|}{ Bus No } & \multicolumn{1}{|c|}{ MGA } \\
\hline Total Generation(MW) & 225.78. \\
\hline Total Load(MW) & 222.78 \\
\hline Loss(MVA) & 6.89 \\
\hline Time(sec) & 0.18 \\
\hline Objective Function & 1087.99 \\
\hline
\end{tabular}

\begin{tabular}{|c|l|}
\hline Bus No & \multicolumn{1}{|c|}{ MGA } \\
\hline Total Generation(MW) & 298.67 \\
\hline Total Load(MW) & 278.90 \\
\hline Loss(MVA) & 20.198 \\
\hline Time(sec) & 0.12 \\
\hline Objective Function & 1044.879 \\
\hline
\end{tabular}

\begin{tabular}{|c|l|}
\hline Bus No & MGA \\
\hline Total Generation(MW) & 278.45 \\
\hline Total Load(MW) & 234.99 \\
\hline Loss(MVA) & 41.78 \\
\hline Time(sec) & 0.57 \\
\hline Objective Function & 1789.08 \\
\hline
\end{tabular}

\begin{tabular}{|c|c|}
\hline Bus No & MGA \\
\hline Total Generation(MW) & 271.74 \\
\hline Total Load(MW) & 269.02 \\
\hline Loss(MVA) & 19.88 \\
\hline Time(sec) & 0.13 \\
\hline Objective Function & 949.21 \\
\hline
\end{tabular}

\section{CONCLUSIONS}

In this paper, a proposed method is found to be more efficient for solving for the locations of a given number of DG devices in a power system. Three different types of DG devices are simulated for energy management: PV, wind and Gas Turbine. A sample 30 bus distribution system has been tested and also an Indian utility system has been taken for consideration for Congestion minimization and loss minimization in which significant improvement in the system performance is justified. Furthermore, the location of DG devices, their types and rated values are optimized for different loading conditions simultaneously by simulated annealing.

The reduction of overall system real power loss and increase in customer benefit significantly improves the system performance. The results reveal the MGA superiority as there is a reduction in the search space and in the execution time; also it changes to reach the global optimal location. This is suitable for searching for several possible solutions simultaneously.

This algorithm is an easy and practical method for the allocation of DG devices in large power system.

\section{REFERENCES}

[1] A.M.EI-Zonkoly, "Optimal placement of multi-distributed generation units including different load models using particle swarm optimization" IET Gener.Transm.Distrib. vol.5, Iss7, pp760-771, 2011.

[2] C.Wang and M.H.Nehrir,"Analytical approaches for optimal placement for optimal placement of distributed generation sources in power systems," IEEE Trans Power Syst. vol.19, no.4, pp.2068-2076, 2004.

[3] Chandrasekar Yammani,Sydulu Maheswarapu,sailajakumari’Optimal placement of Multi DGs in distribution system with considering the DG bus available limits "Energy and Power vol. 2,Iss.1,pp18-23,2012

[4] Durga Gautam, Nadarajah Mithulananthan,"Optimal DG placement in deregulated electricity market. Electric Power Systems ResearchVol.77 pp1627-1636,2007

[5] Electricity market", IEEE Trans Power Syst. vol.19, no.4, pp.206-21 2 2004

[6] Feijoo A.E., Cidras J,:"Modeling of wind farms in the load flow analysis",IEEE Trans.Power Syst.,2000.

[7] G.Celli,F.Pilo,'Penetration level assessment of distributed allocation in MV distribution networks, in: $22^{\text {nd }}$ IEEE PES International conference on Power Industry Computer Applications PICA 2001,Sydney,May 2001,pp 81-86

[8] Gozel,T.Hocaoglu,M.H.,"Än Analytical method for the sizing and sitting of distributed generators in radial system"Int.Journal of Electr.Power Syst.Res.,Vol 79,pp.912-918,2009

[9] H.Zareipour, K.Bhattacharya and C.A, Canizares, "Distributed generation: current status and challenges," IEEE Proceedings of NAPS, 2004.

[10] Iman Ziari, Gerard Ledwich, Senior Member, IEEE, Arindam Ghosh, Fellow, IEEE, and Glenn Platt," Integrated Distribution Systems Planning to Improve Reliability Under Load Growth" IEEE Transactions on power delivery, Vol. 27, No. 2, pp757 2012.

[11] J.H.Teng, "Modelling distributed generations in three phase distributed load flow"

[12] Jabr R.A., Pal B.C.,"Ordinal optimization approach for locating and sizing of distributed generation",IET Generation, Transmission and distribution, Vol.3,Iss.8,pp713-723,2009.

[13] M.F.Akorde, H.Nizam, I.Aris and M.Z.A.AbKadir,"A review of strategies for optimal placement of Distributed Generation in Power Distribution Systems",Research Journal of Applied sciences,Vol5,Iss.2,pp137-145,2011

[14] M.Shahidehpour,H.Yamin,Z.Li Market Operations in Electric Power Systems,John Wiley \&Sons,Inc.,2002.

[15] Mithulanathan, D.G.N, "Optimal DG placement in deregulated electricity market," Electric Power systems research, vol. 77(12), pp. 1627-1636, 2007.

[16] N.S.Rau, Y.H.Wan,'Optimum location of resources in distributed planning , IEEE Trans Power Syst. vol.9,no.4,pp.2014-2020,1994.

[17] S.M.Moghaddas-Tafreshi,Elahe Mashhour "Distributed generation modeling for power flow studies and a three phase unbalanced power flow solution for radial distribution systems considering distributed generation"Electric Power systems research pp.680-686,2009.

[18] R.K.Singh and S.K.Goswami , "Optimum allocation of Distributed Generations based on Nodal pricing for profit, loss reduction and voltage improvement including voltage rise issue," International journal of Electric Power and Energy systems, vol 32 no.6, ,pp 637644,2010

[19] T.Ackermann, G.Andersson and L.Soder," Distributed generation: A definition," Electr.Power Syst. Res., vol.57,no.3 pp.195-204,2001.

[20] W.E.Khattam, K.Bhattacharya, Y.Hegazy, M.M.A.Salama," Optimal investment planning for distributed generation in a competitive

[21] Electricity market", IEEE Trans Power Syst. vol.19, no.4, pp.206-21 22004

[22] J.Baskaran,V.Palanisamy,"Optimal lacation of FACTS device in a power system network considering power loss using genetic algorithm"EE- Pubon line journal,march 7,2005

[23] J.Baskaran, V. Palanisamy, Optimal location of FACTS device in a power system solved by Hybrid Approach , International Journal of Non Linear Analysis: Hybrid Systems and Applications, Elsevier Publication, 65(11) (2006) 2094-2102

[24] R.Zavadil,N.Miller,A.Ellis,Making connections,IEEE Power Energy Mag.3(6),pp-26-37(2005).

[25] I.O.Elgerd,Electric Energy System Theory-An Introduction,McGrawHillInc.,New York,1971. 